\title{
Remote Sensing and Ecosystem Services: Current Status and Future Opportunities for the Study of Bees and Pollination-Related Services
}

\author{
Sara M. Galbraith ${ }^{1,2}$ • L. A. Vierling ${ }^{3}$ - N. A. Bosque-Pérez ${ }^{1}$
}

Published online: 8 October 2015

(C) Springer International Publishing AG 2015

\begin{abstract}
An unprecedented array of observing systems, coupled with ever increasing computing capacity, makes this a golden era for ecologists to study and quantify ecosystem services using remote sensing technology. Here, we review recent studies that utilize remote sensing to understand the supply and demand of ecosystem services, with a specific focus on pollination services by bees in forested and agroforestry contexts. Pollination by bees is a globally threatened ecosystem service that supports the production of food crops and maintains plant biodiversity. We explore how studies that use remote sensing to characterize landscapes, monitor individual organisms, measure biodiversity proxies or species habitat, and describe ecosystem processes may improve modeling of pollination services on spatial scales that match large-scale management efforts, such as forest conservation policy. We then discuss future research opportunities, such as exploring LiDAR and radar for 3-D habitat measurements, mapping phenology in space and time, and direct measurement of pollination events and outcomes.
\end{abstract}

This article is part of the Topical Collection on Remote Sensing

Sara M. Galbraith

sara.marie.galbraith@gmail.com

L. A. Vierling

leev@uidaho.edu

N. A. Bosque-Pérez

nbosque@uidaho.edu

1 Department of Plant, Soil, and Entomological Sciences, University of Idaho, 875 Perimeter Drive, MS 2339, Moscow, ID 83844, USA

2 Centro Agronómico Tropical de Investigación y Enseñaza (CATIE), Sede Central, 7170, Cartago Turrialba 30501, Costa Rica

3 Department of Forest, Rangeland, and Fire Sciences, University of Idaho, 875 Perimeter Drive, MS 1133, Moscow, ID 83844, USA
Keywords Ecosystem services · Remote sensing · Pollination - Bees

\section{Introduction}

Steady advances in technological capacity have created new avenues for using remote sensing techniques to study complex ecological questions. Ecologists have used remotely sensed data to quantify landscape characteristics [1,2], observe physical and biological processes [3, 4], and gauge humanecosystem feedbacks [5]. In many cases, remotely sensed data enable these phenomena to be scaled across time and space, resulting in the development of predictive models useful for mapping and managing the benefits that humans derive from nature, known collectively as ecosystem services $[6,7 \bullet]$.

Ecosystem services include provisioning services, such as the production of lumber or food; regulating services, such as pollination or pest control; supporting services, such as carbon storage and nutrient cycling; and cultural services, such as recreational or spiritual use [8,9]. The Millennium Ecosystem Assessment has spurred a great deal of work over the past decade to understand spatiotemporal patterns of ecosystem service provisioning. Because remote sensing can provide time- and cost-efficient observations at varying spatial and temporal resolutions, it has been adopted as an important tool to study ecosystem services [7•]. The widespread adoption of remote sensing tools for this research can be challenged by the rapid pace of remote sensing technology development, leaving many opportunities for collaborative research among specialists in various disciplines to integrate the two fields of study $[10,11 \bullet \bullet]$.

Arthropods influence the provisioning of several important ecosystem services. However, despite their significant role in many ecosystem services such as pest suppression, 
decomposition, and pollination, arthropods are disproportionately underrepresented among studies that utilize remote sensing techniques [12-14]. To date, application of remotely sensed data to study arthropods has predominantly concerned insect pests. Examples include studies to detect insect damage on forests or croplands [3, 15], follow pest migration $[15,16]$, and examine the movement of insect vectors of pathogens that cause human or plant disease $[17,18]$. Few studies have applied these tools to the study of insects that provide ecosystem services [10].

Pollination, the transfer of genetic material via pollen, is perhaps the most studied ecosystem service that derives from insect activity. Eighty-seven percent of all flowering plant species depend on animals to transfer pollen [19]. Humans directly depend on pollination for food production and economic activities, as $35 \%$ of crop species worldwide depend on pollinators [20]. Bees (superfamily Apoidea) are the most important animal pollinators in the majority of geographic regions $[20,21]$. Unfortunately, their services are threatened by disturbances such as habitat loss, pesticide use, and the spread of pathogens and invasive species [22, 23]. Thus, bees have become a model organism for studying how environmental disturbances impact the provisioning of ecosystem services [24].

Recognizing the contributions that remote sensing approaches can make to the study of pollination, the objectives of this paper are to (1) review key remote sensing concepts and tools that have been applied to studying ecosystem services, particularly those with potential applications for pollination in agroforestry contexts, and (2) identify opportunities and challenges for new research on bees and pollination services. The review is aimed at improving how ecologists adapt existing and new remote sensing technology to the study of pollination services. Though we focus on bees, many of the concepts and approaches presented here are generalizable to other organisms and interactions, including other pollinators (e.g., other insects, birds, and bats), and other mobile ecosystem service providers.

\section{Remote Sensing and Pollination Services: a Brief Primer}

Remote sensing in this review is defined as the science of acquiring, processing, and interpreting data obtained from detection of energy by radiometric sensors [16, 25, 26]. While many applications rely on sensors placed on satellites and aircraft, ground-based sensors [27] and telemetry [28] are also rapidly increasing in use and scientific value. Sensors can be passive or active in nature. Passive sensors measure energy that is reflected by or emitted from matter. Passive approaches include aerial photography and many classes of satellite image data and have produced long-term records for ecosystem monitoring in the shortwave and thermal portions of the electromagnetic spectrum $[29,30]$. In contrast, active remote sensing instruments (e.g., radar and light detection and ranging (LiDAR)) emit pulses of radiation and then measure the amount and timing of the returned energy. Because the timing electronics of active sensors are highly sophisticated and can therefore resolve returns on the order of nanoseconds, the returns measured by these systems can often estimate the physical characteristics of multiple vertical layers of surfaces (e.g., canopy layers) within ecosystems [31, 32].

Remote sensing is a rapidly developing science that spans many disciplines. The number of related tools has grown in both quantity and quality, and as the technology matures, these tools are also becoming more affordable and accessible. Remotely sensed data can be categorized based on spatial, temporal, and spectral resolution and data sources (terrestrial, aerial, or satellite sensors; Table 1). Several resources are available to guide ecologists in selecting data sources and applications $[26,33,34 \cdot \bullet]$.

Biotic pollination is provided by organisms like insects, birds, and mammals [21]. Because animal pollinators are so diverse, one critical step for applying remote sensing tools to the study of pollination is defining the appropriate proxies of the service supply and/or demand of interest for each case (Fig. 1). Good proxies should be quantifiable, sensitive to landscape composition and configuration, temporally and spatially explicit, and scalable [35].

Remotely sensed measures of landscape composition and configuration are commonly used proxies for pollination supply. For example, proximity to forest and other natural areas is positively related to bee abundance and diversity and the provision of pollination services in many crop systems [43-45]. Land use intensity is another possible proxy of pollination service provision. The functional diversity of pollinators (defined as the differences in morphological or behavioral characteristics that determine how pollinators interact with the environment) decreases with increased land use intensity [46] and is correlated with crop yield and biodiversity maintenance [36-39]. In addition, habitat fragmentation can lead to changes at the genetic level [21] even in mobile organisms such as bees [47] and bats [48]. Landscape-mediated genetic effects could therefore impact the ability of a population to respond to disturbance, with associated feedbacks on community composition and pollination outcomes.

Ecosystem services by definition cannot exist outside of human demand [8], so proxies are used to identify where pollination is needed. Two example proxies are the spatial location and pollinator dependency of crops. In this case, the resultant human benefit is a function of biological pollinator dependence of the crop and the total yield or value of crops produced [49]. The presence of a diverse pollinator community may provide additional benefits to farmers, because a more diverse community of pollinators can service changes in farming practices due to market shifts or climate change [8]. 


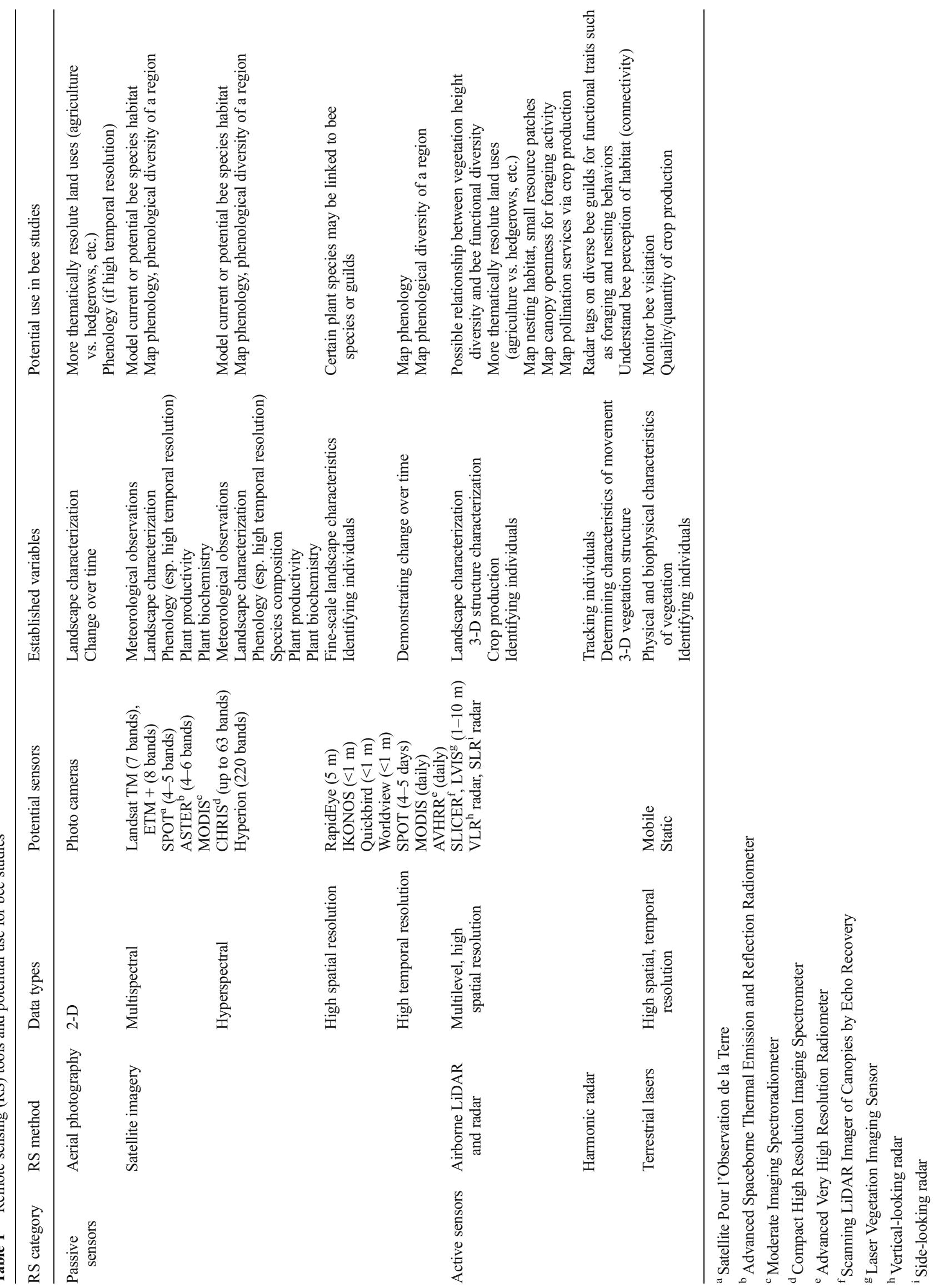


Fig. 1 Conceptual model of pollination service flow that includes supply (measured via bee population metrics), service, and demand. Several bee population measurements are predictors of pollination, but must be matched to a demand to represent a service. See [35] for a more general model of service supply and demand. Evidence for link between bee population metrics and service provision in [36-42]

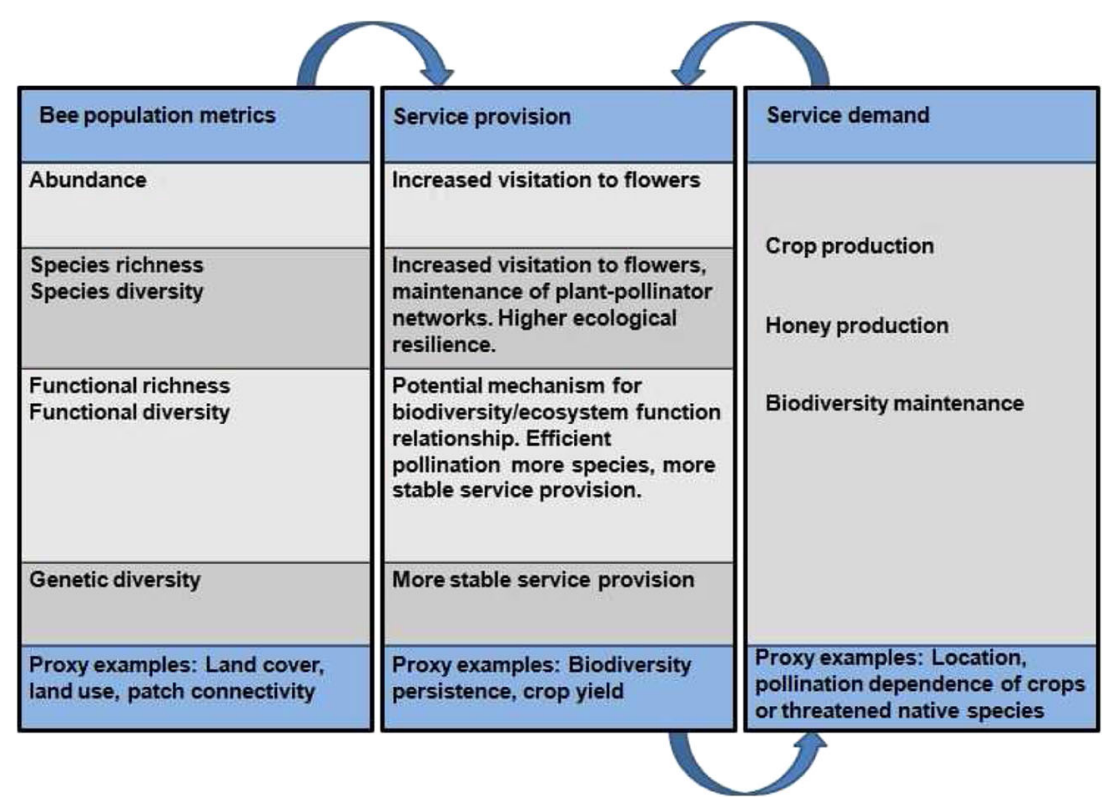

Pollination service demand is also determined by the need for biodiversity maintenance, which sustains a wide range of ecosystem services [50]. Pollinator loss in turn triggers the loss of native pollinator-dependent plants [36], while increased bee functional diversity is correlated with plant persistence [37]. Plant genetic diversity may also increase with pollinator abundance [37]. In turn, biodiversity maintenance has implications for service feedbacks to food crops. Native forest, agroforestry, and silvopastoral systems can all contain high pollinator biodiversity that increase ecosystem service provision within farms [51, 52•].

\section{Remote Sensing Applications Related to the Study of Pollination Services by Bees}

The use of remote sensing in ecology and entomology has been reviewed periodically $[10,11 \bullet \bullet, 12,16,33]$, necessitated by the rapid progress in remote sensing technology and its applications. Here, we focus on recent remote sensing developments and discuss their contributions to understanding the composition of bee populations and the outcome for pollination services.

\section{Landscape Characterization}

One of the most common applications of remote sensing methods in ecology is to characterize 2-D spatial patterns of land cover and land use at scales ranging from the field, to the landscape, to entire regions (Fig. 2) [10, 33]. This process typically involves assessing aerial photography or passive satellite imagery for temporal and spatial trends. Spatial scales of analysis range from the fine-grained (stand size and structure) to intermediate (habitat corridors and edges) and landscape levels (habitat or land use types and distributions within a preponderant type or matrix). Aerial photography, which has been available in the USA since the 1930s, is one of the most spatially and temporally complete records of landscape change [53]. It has played a critical role in quantifying human impacts on the landscape such as deforestation, reforestation, or afforestation $[54,55]$; changing agricultural practices and land use [56]; and urban encroachment [57]. Complementing these data is the ever growing suite of satellite data (e.g., those sensors listed in Table 1), enabling analyses of landscape change using a record of multispectral data reaching back to the early 1970 s.

Landscape characterization is often central to studies of bees and pollination. Aerial photography and passive satellite imagery have been used to test hypotheses of the relationship between native habitat and bee population metrics. The broad spatial coverage of remotely sensed datasets also allows researchers to compare multiple spatial scales and identify the scale of bee response to habitat loss. This is critical for bee research because of the varying foraging ranges and dispersal abilities among bee species [58]. For example, one study used aerial photography and Landsat images to determine that small-scale isolation from forest fragments was not correlated with overall bee species richness and abundance in a tropical system [59]. Interestingly, however, the abundance of meliponines (stingless bees), which have relatively small foraging ranges, did increase with higher proportion of forest cover at short distances $(200-600 \mathrm{~m})$ from the sampling points [59]. 
Fig. 2 Example of scales of data used to understand ecosystem services. Pollination services from bees are used as an example. The final product in this case is a regional map of areas with pollination service provision based on service demand in the landscape and habitat availability from guilds A through N. The final map shows areas of service (gray) and paucity (white) when all maps are layered together

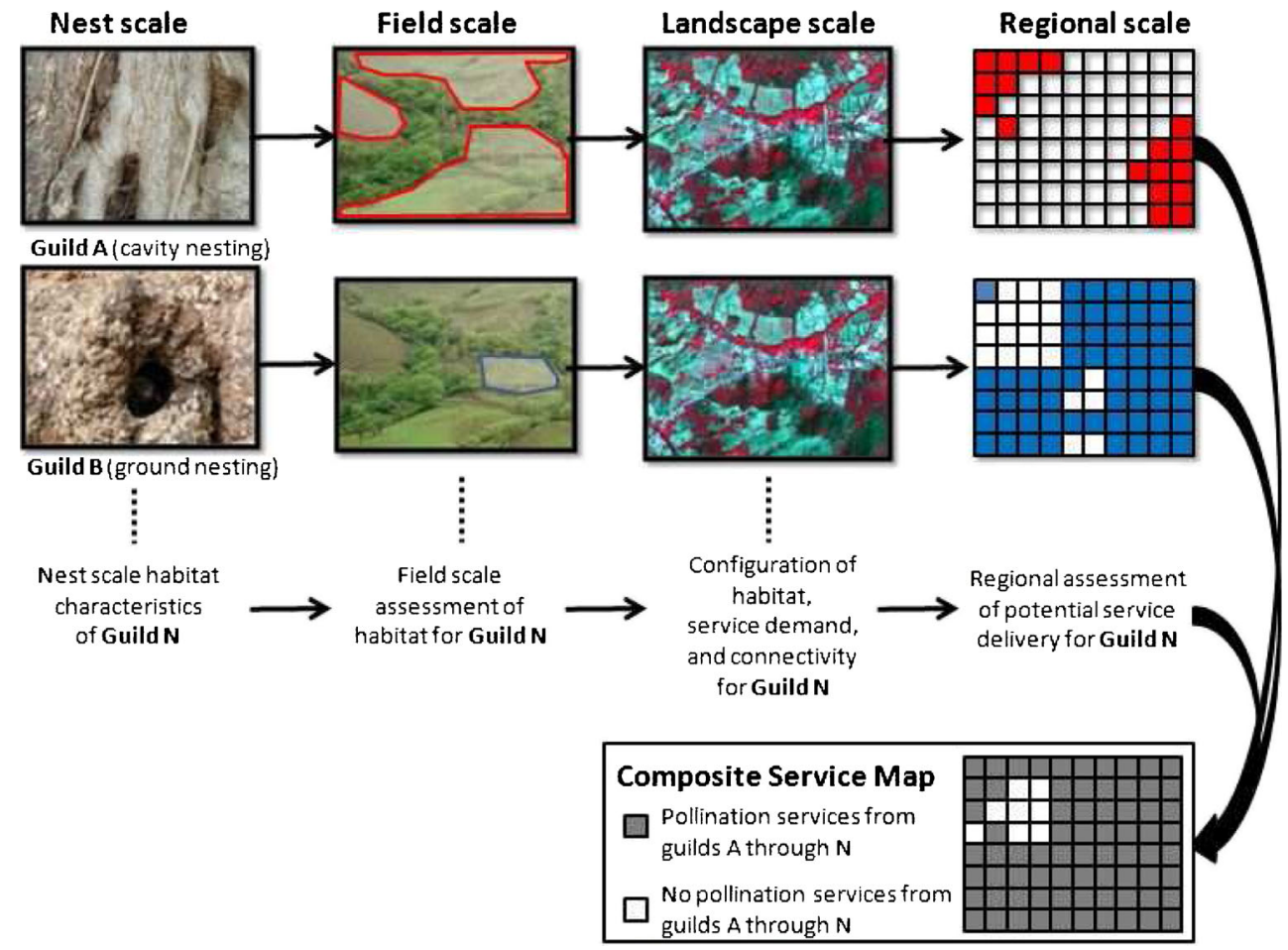

\section{Detection of Individuals}

For decades, ecologists have employed remotely sensed data to identify individual organisms or groups of individuals, especially plants. Aerial photography can be used to quantify the size classes and distributions of individual trees [60] and in some cases to identify trees to species based on color, size, shape, and texture [53]. Using more sophisticated imaging spectrometers capable of measuring hundreds of spectral bands, relationships may be established between individual tree spectral diversity and chemical properties, and as a result, the spectral tools to identify plants even within dense canopies are constantly improving [61].

One specific application to pollinators is the remote monitoring of non-native plant invasions $[11 \bullet \cdot, 62]$. Invasive plants can have positive, negative, or neutral impacts on native bee populations [63]. Non-native plant invasions are of particular interest to pollination research because they can affect the timing and type of floral resources available in an area. If invasive plants do not provide resources for bees, a positive feedback loop can result where the invasive plants increase competition with native plants and reduce the total floral resources available in a landscape. As the feedback continues, the abundance of native plant pollinators, particularly specialists, can be severely affected [64]. Therefore, remote sensing techniques for monitoring plant invasions can be of particular importance to understanding native pollination dynamics and trends.
Remote sensing applications for animals are more limited because of their smaller size and greater agility [25]. This is particularly true for mobile ecosystem service providers, which move within or between habitats [21]. Though rare, there have been studies using remote sensing to directly sense these organisms. Radar has been used for almost a century to locate individual organisms such as birds [65]. This tool can now also be used to identify characteristics of movement such as organism flight speed and height. Vertical-looking radar (VLR), which measures echoes sent back from a stationary vertical beam, can convey information about individuals such as size, shape, and wing-beat frequency [15].

Harmonic radar, which identifies the frequency of a diode, can be used for tagging and tracking of animals [16]. Tags can be light enough for use with medium-sized bees such as honeybees (Apis mellifera). This has contributed to our understanding of how honeybees seek out resources, communicate resource locations, and navigate flight. For example, harmonic radar provided evidence for the "waggle dance": researchers tracked the movements of bees that performed the dance and subsequent foragers, finding that the direction and distance of floral resources were communicated using the dance [15]. Harmonic radar has also been used on beetles $[16,66]$ and additional bee species [67]. Original limitations of this method, such as high cost, large size of the sensor, and difficulty of use, are rapidly subsiding as the technology improves.

Individuals are also tracked using radio telemetry, which is similar to harmonic radar but does not require a stationary 
radar unit or have a fixed detection distance [28]. Radio telemetry requires a battery-powered tag, so it has only recently been successfully employed for the study of insects and can only be used on large bees such as bumble bees [68] and orchid bees [69]. These studies provide information on foraging distance, habitat use, and time of activity of the tagged individual, but are likely still influenced by the increased energy requirements of the individual due to tag weight.

In contrast, LiDAR has been used for population counts and information about movement of individuals without introducing observer bias. Bees can be trained to locate land mines for removal via odor detection, and LiDAR has been used as an effective off-site monitoring method to measure bee location and dwell time over potential mines. LiDAR can be used to detect bee density over time and space and, using a continuous-wave diode laser, can detect the unique wing-beat of the bees [70, 71].

LiDAR data is also useful for directly sensing other pollinating organisms, such as bats. This tool has been used to make exact counts of stationary individuals, like brooding bats in a cave [72], and to measure movement of active individuals. By combining thermal imaging and ground-based LiDAR, Yang and colleagues [73] determined the flight path, velocity, and altitude of big brown bats in a forest plot. Improved methodology will expand the spatial and temporal scale of these experiments and improve their applicability to understanding service provisioning by similar mobile organisms.

\section{Biodiversity Proxies and Species Habitat}

Various aspects of biodiversity relate closely to ecosystem function [74], resilience [75], and ecosystem services [50]. Remote sensing methods can be used for detecting variables that serve as a proxy for biodiversity $[25,26,76]$. Proxies include biogeographic patterns, land cover, topography, vegetation indices, vertical and horizontal vegetation structure, weather events, plant functional traits, and plant chemistry $[34 \cdot \bullet]$.

Remotely sensed biodiversity proxies have improved significantly in recent years. LiDAR can be used to bridge the gap between grain and extent because it has a high spatial resolution and can measure variables from the individual to landscape level $[32,77]$. It can also complement the spectral variation hypothesis, which states that spectral heterogeneity of remotely sensed images can reveal landscape structure and complexity and will signify more niches and therefore greater diversity $[78,79]$. Variables measured with LiDAR reveal vertical vegetation heterogeneity, including metrics such as the standard deviation of vegetation height [14]. This can be linked to biodiversity of animals within the vegetation and has been tested on several animals, including arthropods such as spiders [14] and beetles [13, 80].
Other studies link remote sensing to relevant ecological data to identify the current or potential habitat of a specific taxon (examples in [10, 77, 78, 81]). Vierling et al. [77] outline a five-step process for incorporating remote sensing with habitat characteristics to predict population distributions. Common habitat characteristics derived using LiDAR and radar include vegetation height and canopy density described in 3-D. These variables can also predict certain details about the populations themselves. Hill et al. [82] demonstrated that avian habitat can be determined by remotely sensed vegetation structure and that the body mass of one species in this study could be predicted to an accuracy of $2.1 \%$ based on the habitat data. LiDAR variables were also equally or more useful than variables gathered via fieldwork to predict body size of beetles [13] and occurrence of spider species [14].

Habitat suitability models predict potential habitat for organisms based on habitat requirements [83]. These models have been particularly important for predicting the movement of invasive species, like the invasive Africanized honeybee, which may compete for resources and disrupt specialist plantpollinator mutualisms [84]. A model using 40 data layers, including MODIS (Moderate Resolution Imaging Spectroradiometer) land cover and phenology products, was used to show current Africanized honeybee distribution and predict northward movement in the future [85].

\section{Ecological Processes}

The temporal and spectral properties of remote sensing data are increasingly useful for deriving information on ecological processes (such as photosynthesis, phenology, and plant stress) that occur within a landscape. Derivations of primary productivity can be applied to the study of invertebrates, particularly to understand the distribution of insect herbivores on crops and pathogen vectors [12]. These data are now available at high spatial and temporal scales [86].

Some studies have focused on estimating invertebrate diversity. For example, Levanoni et al. [87] used the normalized difference vegetation index (NDVI) to predict butterfly diversity in a mountainous Mediterranean climate. It is interesting to note that it was not the net primary productivity, but the spatial heterogeneity of productivity, that predicted butterfly richness along the elevation gradient. Because butterflies, like bees, are highly mobile insects and important pollinators and biodiversity indicators, this study demonstrates potential for the use of these variables for other pollinator studies.

Other work has related remotely - sensed vegetation phenological assessments to arthropod ecology. For example, remotely sensed phenology data from MODIS was used to measure the impact of climate change and urbanization on the equilibrium range of Africanized and European honeybees [88]. The greening and browning of leaves (as quantified using MODIS NDVI, enhanced vegetation index, leaf area 
index, and fraction of photosynthetically active radiation products) have been found to coincide with a critical blooming period for the honeybee life cycle. These variables, compared with hive weight, showed resources available in the environment for Africanized bees and enabled researchers to make current and future range maps [88]. Multitemporal remote sensing data can also be highly useful for tracking plant fruiting and flowering phases [see 26,89], which could help quantify temporal and spatial availability of resources for pollinators. As multitemporal remote sensing datasets and analysis procedures are becoming increasingly available and affordable [2], they will be more valuable to ecologists interested in pollination services.

\section{The Future of Remote Sensing and Bees: New Frontiers for Pollination Service Research}

Remote sensing tools have potential for new applications to research of bees and pollination services (Table 1). We highlight opportunities for improved landscape characterization, detection of individuals, invasive species detection, habitat quality and heterogeneity, phenology, and pollination events. In addition, we discuss prospective improvements in the study of pollination demand and outcomes, such as biodiversity maintenance and crop production.

\section{Landscape Characterization}

Although landscape characterization has produced useful hypotheses about bee populations and pollination services, there are several ways that remote sensing techniques may further improve our understanding of these topics across landscapes. New studies could expand the analysis of bee response to landscape change by including different study regions, thematic resolution, and measurements of bee response.

Remotely sensed data hold great potential for expanding bee research geographically. The majority of bee research has taken place in few geographic regions and mostly limited to land uses that are heavily altered by humans [24]. Future research should focus on how bee populations respond to moderate land use changes and in disproportionately understudied areas, such as the tropics [90]. Though remotely sensed data may be more abundant in developed regions of the world, it also allows for cost-efficient research in areas that have historically been understudied or difficult to access.

Remote sensing also allows researchers to match scales of grain and extent with field data. Mismatched scale can mask interesting relationships, particularly in the case of insect habitat $[58,91 \bullet]$. Previous bee research has demonstrated nonintuitive multiscale responses of bee populations to landscape change $[58,59]$. New studies should focus on how pressures from the patch to regional scales can impact bee populations and if and how these variables interact.

Increased temporal, spatial, and spectral resolution of sensors is allowing for greater thematic resolution in land cover characterization while maintaining acceptable levels of mapping accuracy. Maps based on coarse imagery often cannot resolve characteristics critical to bee habitat, such as patchy floral resources and nesting areas. Improved distinction of land uses may improve predictions of bee populations [49]. In existing work, there is little distinction given between types of habitat bees may utilize. Distinguishing among types of forest based on forest age, species composition, or structure may change our understanding of bee response to landscape change. Among human-dominated land uses, separating crop areas from hedgerows, weedy, or fallow areas may better demonstrate resources available to bees.

One of the most important advancements for improving the mapping of pollination services would be understanding how functional traits determine organism response to landscape change. Some ecosystem service work is moving from species-level measurements to emphasizing guild traits that are critical to ecosystem function (Abelleira et al., in review). Plant functional traits are poor predictors of bee abundance, yet good predictors of bee assemblage and structure [92]. While different species are correlated to different plant trait predictors, there is still a paucity of research on which traits are important and why. Bee functional traits such as body size, sociality, nest construction, feeding strategy, and habitat specialization can determine the response to landscape change, as well as the effect on pollination services [38].

\section{Detection of Individuals}

Recent work has emphasized how certain bee behaviors are functional traits that can influence pollination services. For example, bee communication can impact their foraging range and resource selection. Though we have evidence linking bee size to foraging distance [93], estimates still vary, even among well-studied species. Harmonic radar or radio tracking tags on large- to medium-sized bees (other than the well-studied honeybee) could help improve records of foraging range and improve our understanding of the relationship between flight distances and easily measured morphological traits. In addition, harmonic radar might be used to monitor behaviors such as habitat preference and nesting location, particularly for rare species where little data is currently available. This could contribute to our understanding of how bees perceive landscapes and are in turn affected by habitat changes.

\section{Invasive Species}

One of the biggest threats to bee conservation is the introduction of invasive species $[22,84,94]$. The spread of exotic 
honeybees may disrupt mutualistic networks and have implications for the persistence and stability of pollination services in the future [84]. Studies have recorded negative impacts on native bee species but have also observed an increase in pollination services in areas invaded by feral honeybees $[64,94]$. In contrast, native bees are more effective pollinators than honeybees in many agricultural crops globally [95]. While past studies have focused on potential habitat of Africanized bees $[85,88]$, future work should combine local data on bee fauna with datasets on the spatial distribution of domestic honey bees.

Remote sensing methods present researchers with the opportunity to follow the spread of invasive plant species through time across a wide range of spatial scales, and should be used to understand the impact of invasive plant dispersal on bee populations and pollination of native plants or crops. Negative impacts of plant invasion on native bees and plants can be direct, such as competition for floral resources, or indirect, through the introduction of parasites and disease. Tracking of invasive plants holds significant promise for comparing to changes in native bee populations, particularly rare or highly specialized species.

\section{Habitat Quality and Heterogeneity}

Active remote sensing tools such as LiDAR and radar hold potential for measuring canopy architecture and associating these data with variation in faunal diversity of pollinators $[32,77,91 \bullet]$. Few studies to date use LiDAR to understand arthropod populations, and these datasets are underutilized for assessing habitat quality for bees. The connection between vertical diversity of canopy height and biodiversity has been demonstrated for some taxa. The resource heterogeneity hypothesis, which states that ecosystems with more varied structure provide more niches and therefore higher species richness $[91 \bullet, 96]$, could help to predict bee richness. More data is becoming available to study habitat heterogeneity variables in tropical and temperate latitudes using vertical forest structure metrics [97]. Despite connections between bee diversity and metrics of habitat structure such as plant height [98], no studies have yet attempted to test hypotheses such as these with bee population metrics over multiple ecosystems.

Active sensing methods can also be used to predict bee foraging and nesting. The radiation penetration rate at different stages of forest canopy openness, combined with collections of various arthropod indicator taxa, shows that open canopies can have more indicator species than transition or closed forest, including species of bees and wasps [99]. LiDAR can be used to derive temporal variation in insolation values across the full continuum of 3-D canopy locations. Because bee foraging rates respond to changes in temperature and insolation, such 3-D maps may help predict bee foraging activity. New studies should focus on how the spatial distribution of solar radiation in forest, agroforestry, or agricultural land uses impacts pollination services by bees.

Bees nest in various substrates, including soil, pithy stems, and wood cavities (Fig. 2). In the tropics, increased tree diameter is positively related to the presence of stingless bee nests [100]. LiDAR-derived maps of tree basal area and tree height may help predict tree age and the presence of habitat for cavity-nesting bees. Prediction of tree snags and cavities using LiDAR [as in 101] may also provide avenues for assessing the availability of nesting habitat for bees and other pollinators.

\section{Ecological Processes}

Time series of remotely sensed data may provide new insights on how plant phenology affects bee diversity and foraging activity. The spatial and temporal availability of flowering plants is related to availability of resources for bees in a number of habitats. Multitemporal remote sensing data of land surface phenology and productivity proxies can be linked to phenological events such as budbreak, full leaf expansion, flowering, and onset of senescence (Fig. 3) [103]. However, no models have used remotely sensed phenology to predict native bee distributions [85]. The improved spatiotemporal resolution of orbiting and ground-based sensors [104] as well as improved methods for analyzing these data [105] will improve knowledge about the relationship between phenology and bee species distribution and activity.

Terrestrial laser scanners and other ground-based radiometers also hold potential for future advances in pollination service research. Functional trait research can be combined with remotely sensed data to study the relationship between plant structure and function $[103,106]$. Terrestrial LiDAR shows promise for deriving of plant physiological parameters such as foliar chlorophyll [106], nitrogen content [107], water status [108], and photoprotection [4]. Terrestrial lasers and passive narrow-band radiometers may be deployed to detect signs of plant stress [4, 109], pointing to opportunities for exploring potential impacts of plant stressors via changes in floral rewards for pollinators and pollinator visitation.

\section{Pollination Events}

While studies have shown a direct link between the composition and behavior of bee populations to the provisioning of pollination services, it can be tedious to measure the outcome in terms of plant reproduction. A promising future application of remotely sensed data is thus the measurement of visitation and crop production to better quantify the efficiency of pollination. While several field-level methods exist to quantify yield quantity and quality, remote sensing provides opportunities for broad-scale data to be collected that are fine-grained and spatially explicit. For example, data from high-resolution passive commercial sensors can be used to remotely quantify 


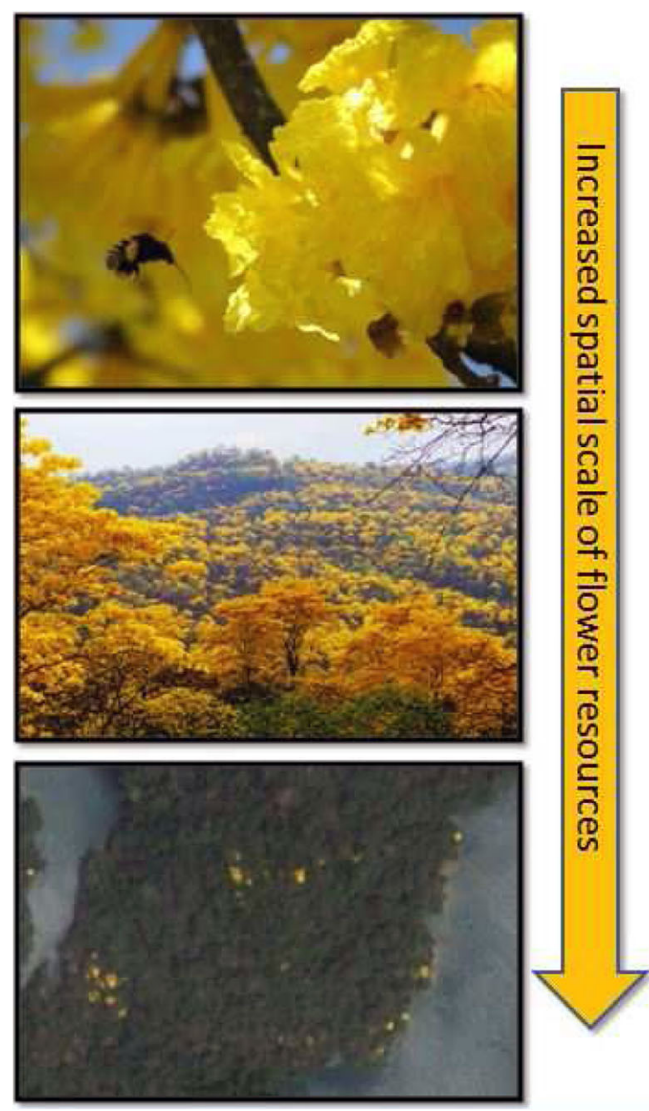

Fig. 3 Remotely sensed data can be used to map flowering events across landscapes that sustain pollinators. This example shows the mass flowering phenology of the tropical tree Tabebuia guayacan at (top) the flower scale, visited by a bee; (center) the landscape scale using oblique digital photography; and (bottom) broader scales using high spatial resolution satellite imagery [see also 89]. This species is pollinated by medium to large bees [102]. Top photo credit: Olga Berrio. Bottom image credit: Digital Globe and NASA

crop production variables within farms [110], which could be compared to variables such as bee visitation, solar radiation, and landscape context.

Bee visitation does not always result in pollination, but pollination biologists often use visitation as a proxy for service provision. There are several issues with visitation observations: the observer's movement or physical presence could influence bee visitation, researchers may cause disturbances in systems where flowers are easily damaged, and observations are limited spatially and temporally. Automated imaging and classification may provide an alternative method for observing bee visitation and therefore hold great potential for understanding pollination services (Fig. 4). The fine (mm- to $\mathrm{cm}$-scale) scale of observation enabled by Terrestrial Laser Scanning (TLS) can detect the 3-D presence of aerial insects, such as mosquitoes, in the environment (Vierling et al., unpublished data). TLS also holds opportunities for comparing bee visitation with environmental variables such as microclimate and landscape context, particularly as automated scanning approaches become more common [see 112].
Remote sensing can also improve our ability to map pollination service demand. Mapping crop production via land use has been done for systems where there is sufficient information on plant-pollinator relationships and crop dependence. For example, GIS-based models are designed with cells that can be given attributes such as potential habitat or pollination dependence [40, 49]. Understanding the importance of bee pollination for biodiversity has historically been more challenging. Remote sensing offers tools for approximating biodiversity in a region, scaling-up local measurements of dependence on pollination services, and quantifying the spatial demand for biodiversity services.

\section{Challenges for Future Research}

\section{Data Selection}

Choosing the appropriate remotely sensing tool or data is one of the biggest challenges for researchers who are not experts in the field. Data widely vary in availability. For example, Landsat data from multiple decades are easily downloadable at little to no cost $[11 \bullet \cdot]$. On the other hand, the spatial and temporal resolution of Landsat data may be too coarse to capture the variables of interest to pollination. More advanced data such as those derived from LiDAR have only recently become available and are especially challenging to obtain in less developed regions of the world [11••, 12].

Tradeoffs also exist among the spectral, spatial, and temporal resolution of data [103]. In some cases, high resolution does not equate to better data. For example, it can be more difficult to assess spectral heterogeneity as a proxy for species diversity using hyperspatial data because of the noise created due to shadows [76, 103]. Higher resolution may also result in higher cost or lower availability relative to the benefit to the study. Collaboration between ecologists and remote sensing experts must advance with the technology in order to ensure that studies take full advantage of these new tools.

\section{Data Analysis and Interpretation}

Analytical challenges may also impede ecologists who are not experienced with the large datasets or corresponding software involved in remote sensing work. Many ecological studies lack explanation on the method used to integrate these data. This includes omission of metadata, data processing methods, description of statistical analysis, and uncertainty [10]. These issues can be exacerbated by lack of training and integration within ecological studies that utilize remote sensing, and could be improved by better collaboration among disciplinary experts $[11 \bullet \bullet$.

It is also critical to distinguish correlating variables in the analysis of habitat suitability models [83]. For example, NDVI 
Fig. 4 Fine-scale, multitemporal remote sensing approaches to capture details of pollinator density, flowering density, and pollination events through time. Remotely sensed data of pollinator density near plants (top panel) using automated imaging and classification methodologies may be combined with imagery on flowering phenology (middle panel) to predict visitation rates. Predicted visitation rates can be validated at individual flowers using digital cameras (bottom panel) [111]

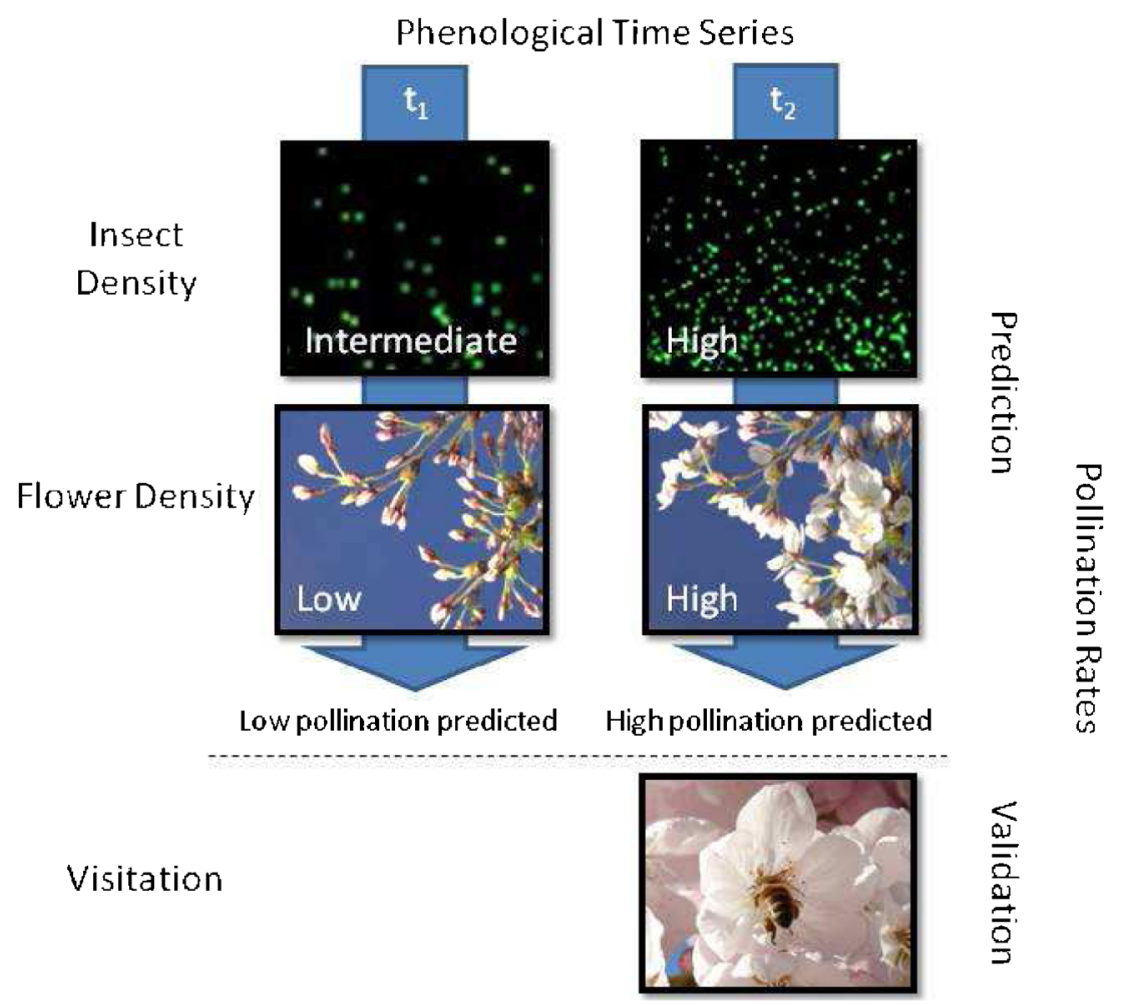

and land cover are related to climate at regional scales. Remote sensing data have the greatest benefit when information is generated that is distinct from climate or other codependent variables. To avoid issues due to codependent variables, researchers must clarify terminology, define the roles of variables a priori, and be specific about model goals in order [83].

\section{Scaling Challenges}

One of the greatest challenges for researchers concerned with ecosystem services is potential scale mismatches among service supply, demand, and human decision-making, such as policy implementation [35]. This is one of the core issues that has given rise to the development of ecosystem service mapping and modeling. Spatially explicit models such as the Natural Capital Project's InVEST Crop Pollination Model have been used to map services based on what is known about bee habitat and foraging, with variable success [40, 49].

There are various challenges that limit generalizability of these models. First, pollination services are locally provided, but the service providers (i.e., bees) are impacted by variables from the local and patch up to the landscape and regional scales [24, 43, 44]. These variables may not be independent and may thus interact across scales. The scaling-up of service provision also depends on clear definition and understanding of variables being measured. This is made more difficult in the case of pollination services because there is a lack of basic ecological data on bee behaviors that are critical to their service, such as foraging, nesting, and seasonality of behavior [49]. The temporal mismatch between ecological field study and availability of new remote sensing images can also present challenges [11••]. Flowering phenology and visitation rates can vary on scales of days to weeks, so time lags might hide important ecological relationships.

\section{Lack of Ecological Data}

More ecological data about plant-pollinator relationships will improve remote sensing-based approaches to understand the location and timing of pollination services. This barrier is greatest in understudied regions of the world, such as the Neotropics [90]. It is estimated that only one third of bee species in the Neotropics have been named [94]. The lack of data on species richness and diversity, taxonomy, distribution, and ecology of bees in these regions limits our ability to understand pollination services. Furthermore, pollination relationships are often poorly understood, even for some common wild plants and crops [22]. Researchers need to expand the range of organisms, landscapes, and ecosystems of pollination studies to better understand local to global impacts of changes in bee populations. Doing so will assist in understanding the varying impacts of remotely sensed estimates of habitat loss due to deforestation, agricultural intensification, and the spread of exotic species on pollination services in understudied regions of the planet. 


\section{Conclusion}

There are burgeoning opportunities for ecologists interested in using remote sensing methods to improve our understanding of bee (and other pollinator) populations, floral resources, and the resultant effects on pollination service provision. The most important step towards applying new remote sensing technology to these studies is improved collaboration of experts from both fields. With cooperation at every step of the research process, from question formulation to analysis and interpretation of results, remote sensing approaches stand to improve our understanding of pollination service provisioning. Resultant maps will in turn allow for better interpretation at multiple scales to support improved pollination service management.

Acknowledgments This work was funded by NSF-IGERT and USAID Borlaug Fellows in Food Security.

\section{Compliance with Ethics Guidelines}

Conflict of Interest Dr. Galbraith reports grants from USAID US Borlaug Fellows in Global Food Security and grants from the National Science Foundation Integrative Graduate Education and Research Traineeship (NSF-IGERT) during the conduct of the study.

Dr. Vierling has nothing to disclose.

Dr. Bosque Perez reports grants from the National Science Foundation Integrative Graduate Education and Research Traineeship (NSF-IGERT) during the conduct of the study.

Human and Animal Rights and Informed Consent This article contains no studies with human or animal subjects performed by the authors.

\section{References}

Papers of particular interest, published recently, have been highlighted as:

- Of importance

-• Of major importance

1. Hansen MC, DeFries RS, Townshend JRG, Sohlberg R. Global land cover classification at $1 \mathrm{~km}$ spatial resolution using a classification tree approach. Int J Remote Sens. 2000;21:1331-64.

2. Kennedy RE, Cohen WB, Schroeder TA. Trajectory-based change detection for automated characterization of forest disturbance dynamics. Remote Sens Environ. 2007;110:370-86.

3. Wulder MA, Dymond CC, White JC, Leckie DG, Carroll AL. Surveying mountain pine beetle damage of forests: a review of remote sensing opportunities. For Ecol Manag. 2006;221:27-41.

4. Magney TS, Eusden SA, Eitel JUH, Logan BA, Jiang J, Vierling LA. Assessing leaf photoprotective mechanisms using terrestrial LiDAR: towards mapping canopy photosynthetic performance in three dimensions. New Phytol. 2014;201:344-56.

5. DeFries RS, Field CB, Fung I, Collatz GJ, Bounoua L. Combining satellite data and biogeochemical models to estimate global effects of human-induced land cover change on carbon emissions and primary productivity. Glob Biogeochem Cycles. 1999;13:803-15.

6. Vihervaara P, Mononen L, Auvinen A-P, Virkkala R, Lü Y, Pippuri I, et al. How to integrate remotely sensed data and biodiversity for ecosystem assessments at landscape scale. Landsc Ecol. 2014;30:501-16.

7. de Araujo Barbosa CC, Atkinson PM, Dearing JA. Remote sensing of ecosystem services: a systematic review. Ecol Indic. $2015 ; 52: 430-43$. Describes and quantifies the number of publications applying remote sensing to ecosystem service questions, the range of variables predicted and how they are applied.

8. Daily GC. Introduction: what are ecosystem services? In: Daily GC, editor. Nature's Services: Societal dependence on natural ecosystems. Washington D.C: Island Press; 1997. pp. 1-11.

9. Millennium Ecosystem Assessment. Ecosystems and human wellbeing: Synthesis. Washington D.C.: Island Press; 2005. vol. 3.

10. Newton AC, Hill RA, Echeverria C, Golicher D, Rey Benayas $\mathrm{JM}$, Cayuela L, et al. Remote sensing and the future of landscape ecology. Prog Phys Geogr. 2009;33:528-46.

11.• Pettorelli N, Laurance WF, O’Brien TG, Wegmann M, Nagendra H, Turner W. Satellite remote sensing for applied ecologists: opportunities and challenges. J Appl Ecol. 2014;51:839-48. This review includes a discussion of established work and new avenues for interdisciplinary applications of passive and active satellite remote sensing tools to ecological studies. Includes a description of remote sensing applications for understanding organism movement and individual species detection.

12. Leyequien E, Verrelst J, Slot M, Schaepman-Strub G, Heitkönig IMA, Skidmore A. Capturing the fugitive: applying remote sensing to terrestrial animal distribution and diversity. Int J Appl Earth Obs Geoinf. 2007;9:1-20.

13. Müller J, Brandl R. Assessing biodiversity by remote sensing in mountainous terrain: the potential of LiDAR to predict forest beetle assemblages. J Appl Ecol. 2009;46:897-905.

14. Vierling KT, Bässler C, Brandl R, Vierling LA, Weiss I, Müller J. Spinning a laser web: predicting spider distributions using LiDAR. Ecol Appl. 2011;21:577-88.

15. Chapman JW, Drake VA, Reynolds DR. Recent insights from radar studies of insect flight. Annu Rev Entomol. 2011;56:33756.

16. Riley JR. Remote sensing in entomology. Annu Rev Entomol. 1989;34:247-71.

17. Hay SI, Packer MJ, Rogers DJ. The impact of remote sensing on the study and control of invertebrate intermediate hosts and vectors for disease. Int J Remote Sens. 1997;18:2899-930.

18. Garcia-Ruiz F, Sankaran S, Maja JM, Lee WS, Rasmussen J, Ehsani R. Comparison of two aerial imaging platforms for identification of Huanglongbing-infected citrus trees. Comput Electron Agric. 2013;91:106-15.

19. Ollerton J, Winfree R, Tarrant S. How many flowering plants are pollinated by animals? Oikos. 2011;120:321-6.

20. Klein AM, Vaissière BE, Cane JH, Steffan-Dewenter I, Cunningham SA, Kremen C, et al. Importance of pollinators in changing landscapes for world crops. Proc R Soc Biol Sci. 2007;274:303-13.

21. Kremen C, Williams NM, Aizen MA, Gemmill-Herren B, LeBuhn G, Minckley R, et al. Pollination and other ecosystem services produced by mobile organisms: a conceptual framework for the effects of land-use change. Ecol Lett. 2007;10:299-314.

22. Brown MJF, Paxton RJ. The conservation of bees: a global perspective. Apidologie. 2009;40:410-6.

23. Potts SG, Biesmeijer JC, Kremen C, Neumann P, Schweiger O, Kunin WE. Global pollinator declines: trends, impacts and drivers. Trends Ecol Evol. 2010;25:345-53. 
24. Winfree R. Global change, biodiversity, and ecosystem services: what can we learn from studies of pollination? Basic Appl Ecol. 2013;14:453-60.

25. Nagendra $\mathrm{H}$. Using remote sensing to assess biodiversity. Int $\mathrm{J}$ Remote Sens. 2001;22:2377-400.

26. Turner W, Spector S, Gardiner N, Fladeland M, Sterling E, Steininger M. Remote sensing for biodiversity science and conservation. Trends Ecol Evol. 2003;18:306-14.

27. Gamon JA, Rahman AF, Dungan JL, Schildhauer M, Huemmrich KF. Spectral Network (SpecNet) - what is it and why do we need it? Remote Sens Environ. 2006;103:227-35.

28. Kissling DW, Pattemore DE, Hagen M. Challenges and prospects in the telemetry of insects. Biol Rev. 2014;89:511-30.

29. Wulder MA, White JC, Goward SN, Masek JG, Irons JR, Herold $\mathrm{M}$, et al. Landsat continuity: issues and opportunities for land cover monitoring. Remote Sens Environ. 2008;112:955-69.

30. Roy DP, Wulder MA, Loveland TR, Woodcock CE, Allen RG, Anderson MC, et al. Landsat-8: science and product vision for terrestrial global change research. Remote Sens Environ. 2014; 145:154-72.

31. Dobson CM, Ulaby FT, LeToan T, Beaudoin A, Kasischke ES, Christensen N. Dependence of radar backscatter on coniferous forest biomass. IEEE Trans Geosci Remote Sens. 1992;30:412-5.

32. Lefsky MA, Cohen WB, Parker GG, Harding DJ. Lidar remote sensing for ecosystem studies. Bioscience. 2002;52:19-30.

33. Kerr JT, Ostrovsky M. From space to species: ecological applications for remote sensing. Trends Ecol Evol. 2003;18:299-305.

34.• Andrew ME, Wulder MA, Nelson TA. Potential contributions of remote sensing to ecosystem service assessments. Prog Phys Geogr. 2014;38:328-53. Description of the remote sensing products available that offer more direct estimates of ecological properties controlling ecosystem services than those currently represented in most studies. Includes a discussion of biodiversity proxies and phenology measurements useful for bee and/or pollination studies.

35. Burkhard B, Kroll F, Nedkov S, Müller F. Mapping ecosystem service supply, demand and budgets. Ecol Indic. 2012;21:17-29.

36. Biesmeijer JC, Roberts SPM, Reemer M, Ohlemüller R, Edwards $\mathrm{M}$, Peeters $\mathrm{T}$, et al. Parallel declines in pollinators and insectpollinated plants in Britain and the Netherlands. Science. 2006;313:351-4.

37. Fontaine C, Dajoz I, Meriguet J, Loreau M. Functional diversity of plant-pollinator interaction webs enhances the persistence of plant communities. PLoS Biol. 2006;4:129-35.

38. Hoehn P, Tscharntke T, Tylianakis JM, Steffan-Dewenter I. Functional group diversity of bee pollinators increases crop yield. Proc R Soc B. 2008;275:2283-91.

39. Martins KT, Gonzalez A, Lechowicz MJ. Pollination services are mediated by bee functional diversity and landscape context. Agric Ecosyst Environ. 2015;200:12-20.

40. Lonsdorf E, Kremen C, Ricketts T, Winfree R, Williams N, Greenleaf S. Modelling pollination services across agricultural landscapes. Ann Bot. 2009;103:1589-600.

41. Luck GW, Daily GC, Ehrlich PR. Population diversity and ecosystem services. Trends Ecol. Evol. 2003;18:331-6.

42. Mori AS, Furukawa T, Sasaki T. Response diversity determines the resilience of ecosystems to environmental change. Biol Rev. 2013;88:349-64.

43. Kremen C, Williams NM, Bugg RL, Fay JP, Thorp RW. The area requirements of an ecosystem service: crop pollination by native bee communities in California. Ecol Lett. 2004;7:1109-19.

44. Ricketts TH, Regetz J, Steffan-Dewenter I, Cunningham SA, Kremen C, Bogdanski A, et al. Landscape effects on crop pollination services: are there general patterns? Ecol Lett. 2008;11: 499-515.
45. Garibaldi LA, Steffan-Dewenter I, Kremen C, Morales JM, Bommarco R, Cunningham SA, et al. Stability of pollination services decreases with isolation from natural areas despite honey bee visits. Ecol Lett. 2011;14:1062-72.

46. Rader R, Bartomeus I, Tylianakis JM, Laliberté E. The winners and losers of land use intensification: pollinator community disassembly is non-random and alters functional diversity. Divers Distrib. 2014;20:908-17.

47. Davis ES, Murray TE, Fitzpatrick N, Brown MJF, Paxton RJ. Landscape effects on extremely fragmented populations of a rare solitary bee, Colletes floralis. Mol Ecol. 2010;19:4922-35.

48. Ripperger SP, Tschapka M, Kalko EKV, Rodriguez-Herrera B, Mayer F. Life in a mosaic landscape: anthropogenic habitat fragmentation affects genetic population structure in a frugivorous bat species. Conserv Genet. 2013;14:925-34.

49. Zulian G, Maes J, Paracchini ML. Linking land cover data and crop yields for mapping and assessment of pollination services in Europe. Land. 2013;2:472-92.

50. Hooper DU, Chapin FSI, Ewel JJ, Hector A, Inchausti P, Lavorel $\mathrm{S}$, et al. Effects of biodiversity on ecosystem functioning: a consensus of current knowledge. Ecol Monogr. 2011;75:3-35.

51. Tscharntke T, Sekercioglu CH, Dietsch TV, Sodhi NS, Hoehn P, Tylianakis JM. Landscape constraints on functional diversity of birds and insects in tropical agroecosystems. Ecology. 2008;89: 944-51.

52. Blitzer EJ, Dormann CF, Holzschuh A, Klein AM, Rand TA, Tscharntke T. Spillover of functionally important organisms between managed and natural habitats. Agric Ecosyst Environ. 2012;146:34 43. Review of studies done on five functionally important trophic groups that analyze movement across habitats, particularly between agricultural and natural systems. Highlights the need for more studies on the movement from agricultural towards natural systems, such as forests.

53. Morgan JL, Gergel SE, Coops NC. Aerial photography: a rapidly evolving tool for ecological management. Bioscience. 2010;60: 47-59.

54. Asner G, Archer S, Hughes RF, Ansley RJ, Wessman CA. Net changes in regional woody vegetation cover and carbon storage in Texas drylands, 1937-1999. Glob Chang Biol. 2003;9:316-35.

55. Strand EK, Vierling LA, Smith AMS, Bunting SC. Net changes in aboveground woody carbon stock in western juniper woodlands, 1946-1998. J Geophys Res. 2008;113:1-13.

56. Thomilnson JR. Land-use dynamics in a post-agricultural Puerto Rican landscape (1936-1988). Biotropica. 1996;28:525-36.

57. Robinson L, Newell JP, Marzluff JM. Twenty-five years of sprawl in the Seattle region: growth management responses and implications for conservation. Landsc Urban Plan. 2005;71:51-72.

58. Steffan-Dewenter I, Munzenberg CB, Thies C, Tscharntke T. Scale-dependent effects of landscape context on three pollinator guilds. Ecology. 2002;83:1421-32.

59. Brosi BJ, Daily GC, Shih TM, Oviedo F, Durán G. The effects of forest fragmentation on bee communities in tropical countryside. $\mathrm{J}$ Appl Ecol. 2007;45:773-83.

60. Strand EK, Smith AMS, Bunting SC, Vierling LA, Hann DB, Gessler PE. Wavelet estimation of plant spatial patterns in multitemporal aerial photography. Int J Remote Sens. 2006;27: 2049-54.

61. Asner GP, Martin RE, Ford AJ, Metcalfe DJ, Liddell MJ. Leaf chemical and spectral diversity in Australian tropical forests. Ecol Appl. 2009;19:236-53.

62. Young KE, Abbott LB, Caldwell CA, Schrader TS. Estimating suitable environments for invasive plant species across large landscapes: a remote sensing strategy using Landsat 7 ETM +. Int J Biodivers Conserv. 2013;5:122-34. 
63. Williams NM, Cariveau D, Winfree R, Kremen C. Bees in disturbed habitats use, but do not prefer, alien plants. Basic Appl Ecol. 2011;12:332-41.

64. Stout JC, Morales CL. Ecological impacts of invasive alien species on bees. Apidologie. 2009;40:388-409.

65. Lack D, Varley GC. Detection of birds by radar. Nature. 1945;156: 446.

66. ONeal ME, Landis DA, Rothwell E. Tracking insects with harmonic radar: a case study. Am Entomol. 2004;50:212-8.

67. Osborne JL, Clark SJ, Morris RJ, Williams IH, Riley JR, Smith $\mathrm{AD}$, et al. A landscape-scale study of bumble bee foraging range and constancy using harmonic radar. J Appl Ecol. 1999;36:51933.

68. Hagen M, Wikelski M, Kissling WD. Space use of bumblebees (Bombus spp.) revealed by radio-tracking. PLoS One. 2011;6:110.

69. Wikelski M, Moxley J, Eaton-Mordas A, López-Uribe MM, Holland R, Moskowitz D, et al. Large-range movements of neotropical orchid bees observed via radio telemetry. PLoS One. 2010;5:5-10.

70. Shaw J, Seldomridge N, Dunkle D, Nugent P, Spangler L, Bromenshenk J, et al. Polarization lidar measurements of honey bees in flight for locating land mines. Opt Express. 2005;13: 5853-63.

71. Hoffman DS, Nehrir AR, Repasky KS, Shaw JA, Carlsten JL. Range-resolved optical detection of honeybees by use of wingbeat modulation of scattered light for locating land mines. Appl Opt. 2007;46:3007-12.

72. Azmy SN, Sah SAM, Shafie NJ, Ariffin A, Majid Z, Ismail MNA, et al. Counting in the dark: non-intrusive laser scanning for population counting and identifying roosting bats. Sci Rep. 2012;2:1-4.

73. Yang X, Schaaf C, Strahler A, Kunz T, Fuller N, Betke M, et al. Study of bat flight behavior by combining thermal image analysis with a LiDAR forest reconstruction. Can J Remote Sens. 2013;39.

74. Hillebrand H, Matthiessen B. Biodiversity in a complex world: consolidation and progress in functional biodiversity research. Ecol Lett. 2009;12:1405-19.

75. Folke C, Carpenter S, Walker B, Scheffer M, Elmqvist T, Gunderson L, et al. Regime shifts, resilience, and biodiversity in ecosystem management. Annu Rev Ecol Evol Syst. 2004;35:55781.

76. Rocchini D, Balkenhol N, Carter GA, Foody GM, Gillespie TW, $\mathrm{He} \mathrm{KS}$, et al. Remotely sensed spectral heterogeneity as a proxy of species diversity: recent advances and open challenges. Ecol Inform. 2010;5:318-29.

77. Vierling KT, Vierling LA, Gould WA, Martinuzzi S, Clawges RM. Lidar: shedding new light on habitat characterization and modeling. Front Ecol Environ. 2008;6:90-8.

78. Bergen KM, Goetz SJ, Dubayah RO, Henebry GM, Hunsaker CT, Imhoff ML, et al. Remote sensing of vegetation 3-D structure for biodiversity and habitat: review and implications for lidar and radar spaceborne missions. J Geophys Res. 2009;114:1-13.

79. Oldeland J, Wesuls D, Rocchini D, Schmidt M, Jürgens N. Does using species abundance data improve estimates of species diversity from remotely sensed spectral heterogeneity? Ecol Indic. 2010;10:390-6.

80. Work T, St Onge B, Jacobs J. Response of female beetles to LIDAR derived topographic variables in eastern boreal mixedwood forests (Coleoptera, Carabidae). Zookeys. 2011;147: 623

81. Bradbury RB, Hill RA, Mason DC, Hinsley SA, Wilson JD, Balzter $\mathrm{H}$, et al. Modelling relationships between birds and vegetation structure using airborne LiDAR data: a review with case studies from agricultural and woodland environments. Ibis. 2005; 147:443-52.
82. Hill RA, Hinsley SA, Gaveau DLA, Bellamy PE. Predicting habitat quality for great tits (Parus major) with airborne laser scanning data. Int J Remote Sens. 2004;25:4851-5.

83. Bradley BA, Olsson AD, Wang O, Dickson BG, Pelech L, Sesnie SE, et al. Species detection vs. habitat suitability: are we biasing habitat suitability models with remotely sensed data? Ecol Model. 2012;244:57-64.

84. Dohzono I, Yokoyama J. Impacts of alien bees on native plantpollinator relationships: a review with special emphasis on plant reproduction. Appl Entomol Zool. 2010;45:37-47.

85. Jarnevich CS, Esaias WE, Ma PLA, Jeffery T, Nickeson JE, Stohlgren TJ, et al. Regional distribution models with lack of proximate predictors: Africanized honeybees expanding north. Divers Distrib. 2014;20:193-201.

86. Running SW, Nemani RR, Heinsch FA, Zhao M, Reeves M, Hashimoto H. A continuous satellite-derived measure of global terrestrial primary production. Bioscience. 2004;547:60.

87. Levanoni O, Levin N, Pe'er G, Turbé A, Kark S. Can we predict butterfly diversity along an elevation gradient from space? Ecography. 2011;34:372-83.

88. Nightingale JM, Esaias WE, Wolfe RE, Nickeson JE, Ma PLA. Assessing honey bee equilibrium range and forage supply using satellite-derived phenology. Geosci Remote Sens Symp. 2008;3: 763-6.

89. Sánchez-Azofeifa A, Rivard B, Wright J, Feng J-L, Li P, Chong $\mathrm{MM}$, et al. Estimation of the distribution of Tabebuia guayacan (Bignoniaceae) using high-resolution remote sensing imagery. Sensors. 2011;11:3831-51.

90. Archer CR, Pirk CWW, Carvalheiro LG, Nicolson SW. Economic and ecological implications of geographic bias in pollinator ecology in the light of pollinator declines. Oikos. 2014;123:401-7.

91. Müller J, Bae S, Röder J, Chao A, Didham RK. Airborne LiDAR reveals context dependence in the effects of canopy architecture on arthropod diversity. For Ecol Manag. 2014;312:129-37. Links information collected at landscape and local scales with forest beetle assemblages. LiDAR-derived variables had high predictive power for beetles sampled, including mean body size and species composition. Shows potential for using LiDAR to understand arthropod distributions in complex forested habitat.

92. Pakeman RJ, Stockan J. Using plant functional traits as a link between land use and bee foraging abundance. Acta Oecol. 2013;50:32-9.

93. Greenleaf SS, Williams NM, Winfree R, Kremen C. Bee foraging ranges and their relationship to body size. Oecologia. 2007;153: 589-96.

94. Freitas BM, Imperatriz-Fonseca VL, Medina LM, Kleinert AMP, Galetto L, Nates-Parra G, et al. Diversity, threats and conservation of native bees in the Neotropics. Apidologie. 2009;40:332-46.

95. Garibaldi LA, Steffan-Dewenter I, Winfree R, Aizen MA, Bommarco R, Cunningham SA, et al. Wild pollinators enhance fruit set of crops regardless of honey bee abundance. Science. 2013;339:1608-11.

96. Rosenzweig ML. Species diversity in space and time. Cambridge: Cambridge University Press; 1995.

97. Sun G, Ranson KJ, Kimes DS, Blair JB, Kovaks KV. Forest vertical structure from GLAS: an evaluation using LVIS and SRTM data. Remote Sens Environ. 2008;112:107-17.

98. Frund J, Dormann CF, Holzschuh AH, Tscharntke T. Bee diversity effects on pollination depend on functional complementarity and niche shifts. Ecology. 2013;94:2042-54.

99. Lehnert LW, Bässler C, Brandl R, Burton PJ, Müller J. Conservation value of forests attacked by bark beetles: highest number of indicator species is found in early successional stages. J Nat Conserv. 2013;21:97-104. 
100. Eltz T, Brühl CA. Determinants of stingless bee nest density in lowland dipterocarp forests of Sabah, Malaysia. Popul Ecol. 2002;131:27-34.

101. Martinuzzi S, Vierling LA, Gould WA, Falkowski MJ, Evans JS, Hudak AT, et al. Mapping snags and understory shrubs for a LiDAR-based assessment of wildlife habitat suitability. Remote Sens Environ. 2009;113:2533-46.

102. Bawa KS, Bullock SH, Perry DR, Coville RE, Grayum, MH. Reproductive biology of tropical lowland rainforest trees. II. Pollination systems. Am J Bot. 1985;72:346-56.

103. Homolová L, Malenovský Z, Clevers JGPW, García-Santos G, Schaepman ME. Review of optical-based remote sensing for plant trait mapping. Ecol Complex. 2013;15:1-16.

104. Garrity SR, Vierling LA, Bickford K. A simple filtered photodiode instrument for continuous measurement of narrowband NDVI and PRI over vegetated canopies. Agric For Meteorol. 2010;150:48996.

105. Sweet SK, Griffin KL, Steltzer H, Gough L, Boelman NT. Greater deciduous shrub abundance extends tundra peak season and increases modeled net CO2 uptake. Glob Chang Biol. 2014;21: 2394-409.

106. Eitel JUH, Vierling LA, Long DS. Simultaneous measurements of plant structure and chlorophyll content in broadleaf saplings with a terrestrial laser scanner. Remote Sens Environ. 2010;114:2229-37.

107. Eitel JUH, Magney TS, Vierling LA, Huggins D, Brown T. Lidar remote sensing advances quantification of wheat biomass and nitrogen status during the critical early growing season. Field Crop Res. 2014;159:21-32.

108. Gaulton R, Danson FM, Ramirez FA, Gunawan O. The potential of dual-wavelength laser scanning for estimating vegetation moisture content. Remote Sens Environ. 2013;132:32-9.

109. Wong CYS, Gamon JA. Three causes of variation in the photochemical reflectance index (PRI) in evergreen conifers. 2015;206:187-95.

110. Furfaro R, Ganapol BD, Johnson LF, Herwitz SR. Neural network algorithm for coffee ripeness evaluation using airborne images. Appl Eng Agric. 2007;23:379-87.

111. Suetsugu K, Hayamizu M. Moth floral visitors of the three rewarding Platanthera orchids revealed by interval photography with a digital camera. J Nat Hist. 2014;48:1103-9.

112. Eitel JUH, Vierling LA, Magney TS. A lightweight, low cost autonomously operating terrestrial laser scanner for quantifying and monitoring ecosystem structural dynamics. Agric For Meteorol. 2013;180:86-96. 